\title{
Penile schwannoma mistaken for hemangioma: a rare case report and literature review
}

\author{
Si Hyun Kim ${ }^{1}$, Hyein Ahn' ${ }^{2}$ Ki Hong Kim ${ }^{1}$, Doo Sang Kim ${ }^{1}$, Hee Jo Yang ${ }^{1}$ \\ ${ }^{1}$ Department of Urology, Soonchunhyang University Cheonan Hospital, Soonchunhyang University College of Medicine, Cheonan, Korea; \\ ${ }^{2}$ Department of Pathology, Soonchunhyang University Cheonan Hospital, Soonchunhyang University College of Medicine, Cheonan, Korea \\ Correspondence to: Hee Jo Yang, MD. Associate professor, Department of Urology, Soonchunhyang University Cheonan Hospital, Soonchunhyang \\ University College of Medicine, 31 Suncheonhyang 6-gil, Dongnam-gu, Cheonan 31151, Korea. Email: c78154@schmc.ac.kr.
}

\begin{abstract}
Penile neoplasm is uncommon. Schwannomas of the penis are especially rare. For this reason, it is difficult to get an accurate impression to enable decision making. This report primarily deals with the mistaken diagnosis of hemangioma, to the surgery, and the follow-up in real-world. A 38-year-old male patient presented with a palpable mass in the penile root that increased in size with erection. One year after the mass had been found, the patient visited the hospital and complained that the mass was growing. Moreover, the patient explained that the mass seemed to increase during penile erection. On physical examinations, a $2 \mathrm{~cm}$ mass without tenderness was palpated in the left penoscrotal junction. About $2.1 \mathrm{~cm}$ in size, an isoechoic mass was observed next to the corpus cavernosum on ultrasonography. There was high vascularity inside of the mass. Excision and biopsy were decided upon. Following surgery, a schwannoma was confirmed by pathology. After three months, the patient did not complain of any symptoms and had normal erectile function. Most of these tumors are benign. By December 2020, 40 cases were reported, of which 6 were diagnosed as malignant. The most frequent occurrence site is the penile shaft. In all cases, surgical resection was performed and no recurrence was found. The aim of this case report is to assist clinicians in choosing the best treatment option when faced with this rare condition by discussing the radiological, pathological, and clinical course.
\end{abstract}

Keywords: Schwannoma; neurilemmoma; hemangioma; penile neoplasms; penis; case report

Submitted Mar 18, 2021. Accepted for publication May 05, 2021.

doi: $10.21037 /$ tau-21-239

View this article at: http://dx.doi.org/10.21037/tau-21-239

\section{Introduction}

Schwannomas are neoplasms that mostly originate from Schwann cells, which are responsible for maintaining the myelin sheath of peripheral neurons. A loss of function in the neurofibromatosis type 2 (NF2) gene, which codes for the merlin protein, often gives rise to these tumors (1). It can be benign or malignant in nature, but most are benign (2).

Schwannomas can occur in various parts of the body and are most common in the head and limbs. The overall incidence of all schwannomas was 1 per 50,000 people, and the incidence of intracranial schwannomas was 1 per 80,000 people (3). The incidence of peripheral schwannomas was reported to be 0.6 per 100,000 people (4). It is especially rare in the penis. Because of this, when a urologist encounters a patient with a penile schwannoma in the clinic, it is often difficult to make an accurate diagnosis and can be mistaken for something else. Here, we report on a case of penile schwannoma mistaken for a hemangioma, including a detailed description of the clinical course, surgery and pathology. Institutional review board approval (No. 202006-008) was granted. The authors have read the CARE reporting checklist, and the manuscript was prepared and revised according to the CARE reporting checklist (available at http://dx.doi.org/10.21037/tau-21-239). 

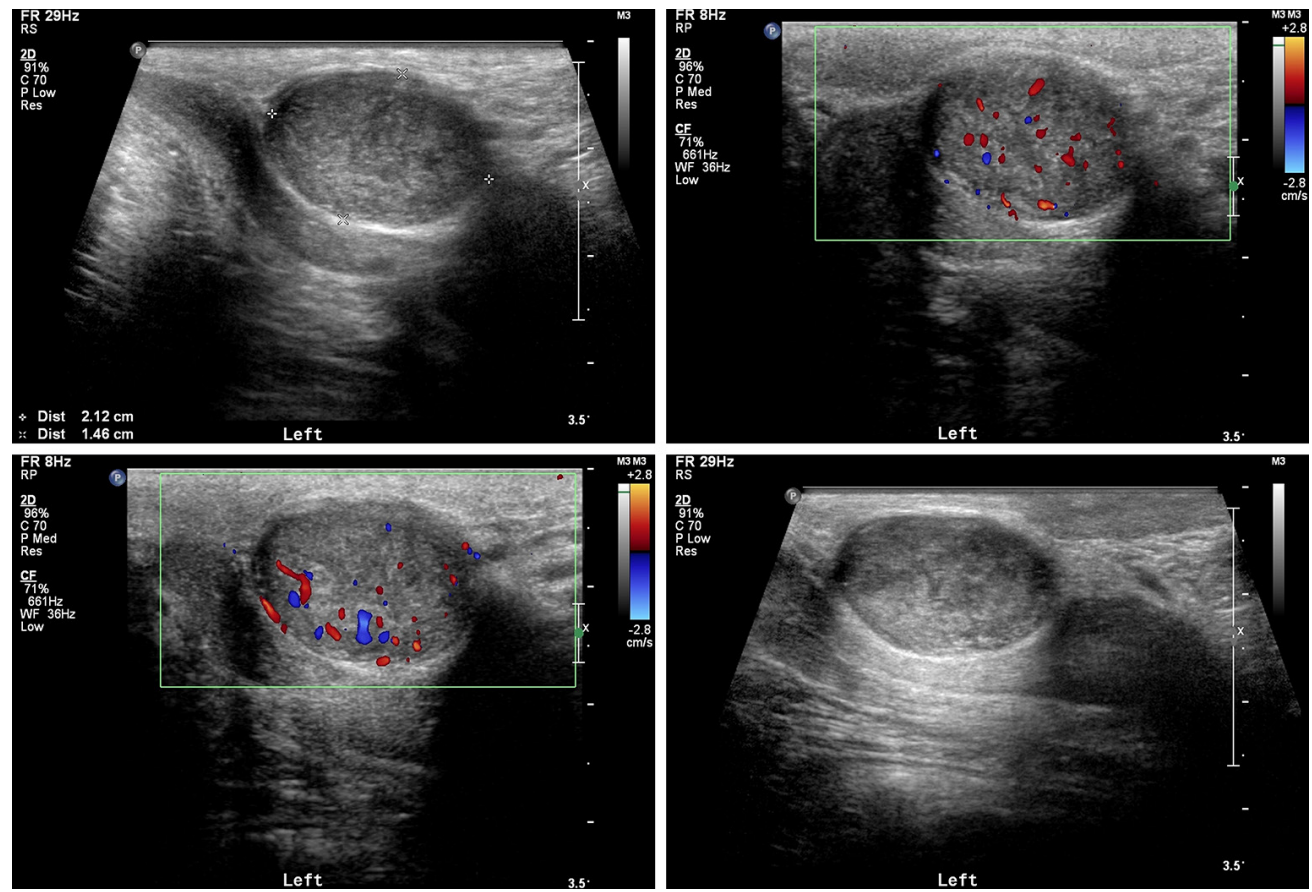

Figure 1 An isoechoic oval-shaped mass showed hypervascularity on penile Doppler ultrasonography.

\section{Case presentation}

A 38-year-old patient, with no comorbidities, presented with a palpable mass in the ventral side of the left penoscrotal junction. He had discovered this mass one year previously. The mass was about $1 \mathrm{~cm}$. He said that the mass size increased during penile erection and was without pain. The patient had no previous history of scrotal or penile trauma. He also had no history of spinal cord diseases. The patient had no special personal and family history. On physical examination, a firm mass about $2 \mathrm{~cm}$, without tenderness, was palpated at the left penoscrotal junction, and there was no lymphadenopathy in the groin region. The mass was movable and did not adhere to adjacent tissue. Blood test and urine chemistry findings were within normal ranges.

Penile ultrasonography showed about a $2.1-\mathrm{cm}$ isoechoic mass around the corpus cavernosum of the penis, and it was located to the left ventral side of penoscrotal junction with posterior acoustic enhancement. On Doppler ultrasonography, there was high vascularity inside of the mass. The mass had a distinct boundary that distinguished it from the tunica albuginea (Figure 1). The first impression was hemangioma. On physical examinations and penile ultrasonography, surgery for pathological confirmation was performed after obtaining informed consent from the patient.
The operation was performed under general anesthesia. After the patient had been placed in a supine position, the usual preparations were done using povidone and disposable surgical drapes. The skin above the mass was incised vertically. Alveolar tissues were retracted, and Buck's fascia was exposed. There was an adhesion that made it difficult to separate the Buck's fascia surrounding the mass. However, when the Buck's fascia was dissected, it was easy to separate the mass from the surrounding tissue. It was located between the corpus cavernosum and the spongiosum, inside of Buck's fascia (Figure 2). It had clear margin distinguished from the tunica albuginea of the corpus cavernosum and corpus spongiosum. The mass was firmly palpated. The major vascular structures supplying the mass were not observed. Following excision, the mass was oval shaped with a yellowish surface. It was $2 \mathrm{~cm} \times 1.5 \mathrm{~cm}$ (Figure 3 ).

Hematoxylin-eosin (H\&E) staining of the tumor demonstrated the typical biphasic pattern composed of alternating Antoni A and Antoni B areas. Tumor cells showed nuclear palisading with tapered ends interspersed with collagen fibers. In immunohistochemical staining of S-100, strong and diffuse expression of tumor cells was observed (Figure 4).

During a three-month follow-up period subsequent to the operation, the patient urinated well and had normal 

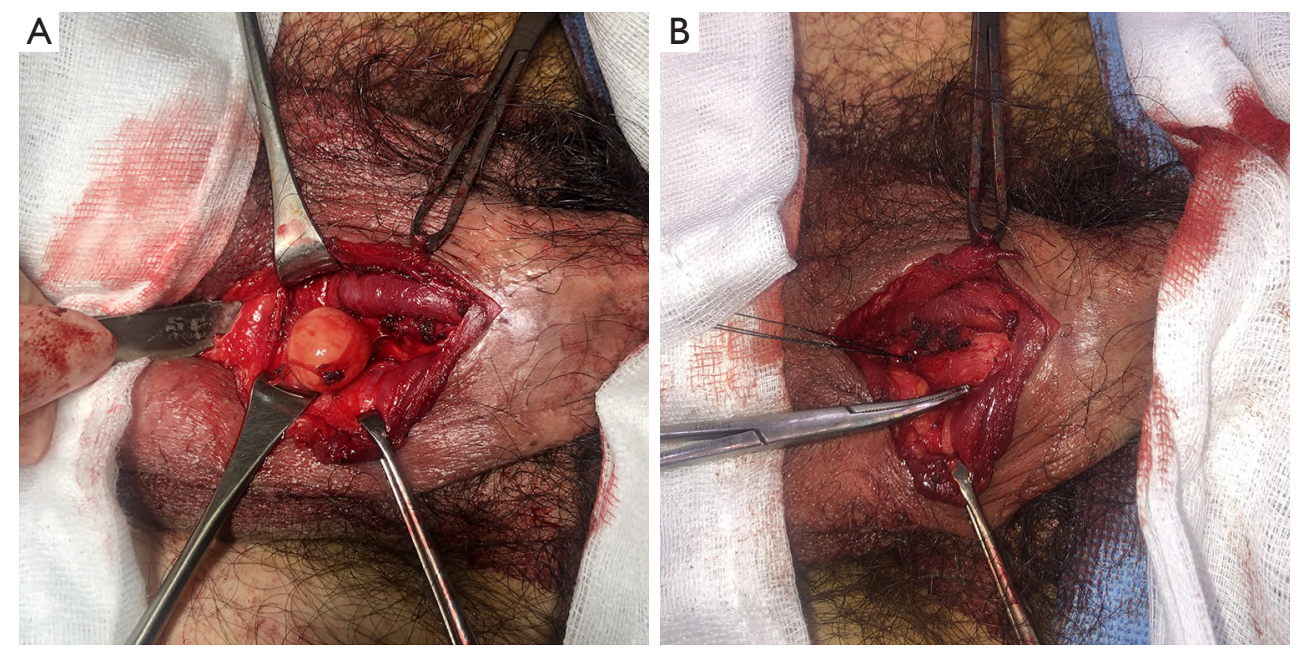

Figure 2 A yellow mass was observed that was well distinguished from the surrounding tissues.
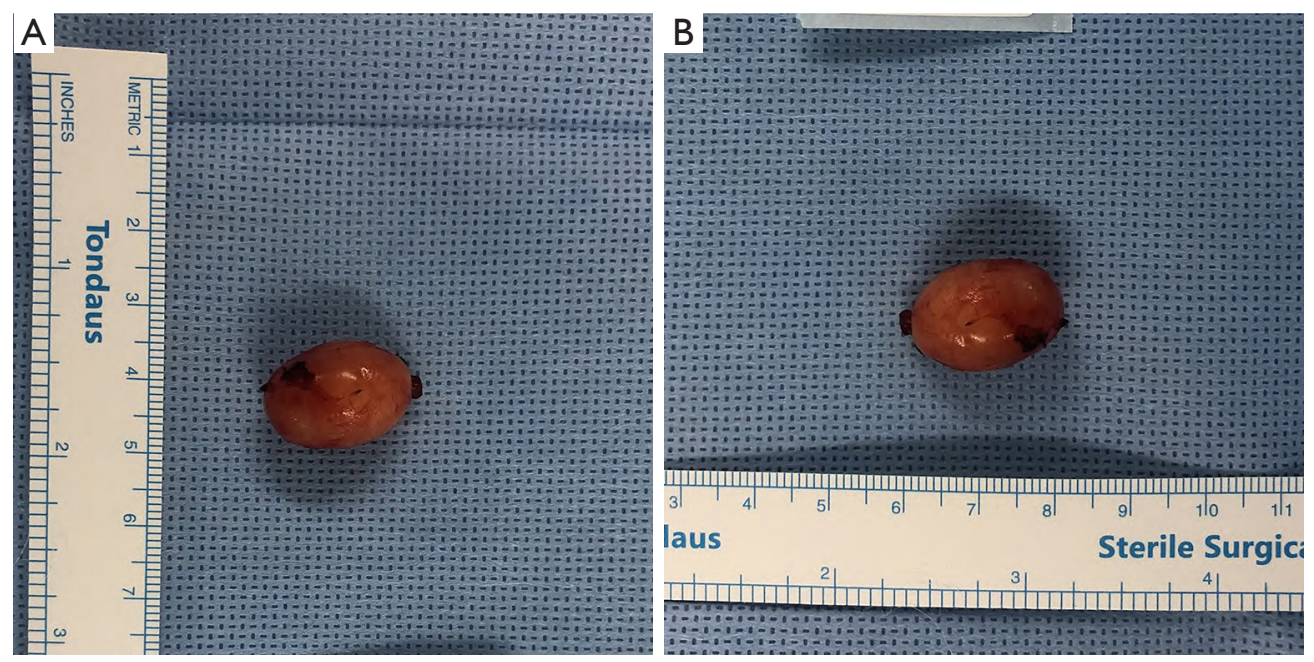

Figure 3 An oval shaped mass with a long 2-cm axis and short 1-cm axis.

erectile function. Tumor recurrence or metastasis was not observed on contrast-enhanced abdominal computed tomography (CT) during the follow up period. This is a timeline showing the patient follow-up process (Figure 5).

All procedures performed in studies involving human participants were in accordance with the ethical standards of the institutional and/or national research committee(s) and with the Helsinki Declaration (as revised in 2013). Written informed consent was obtained from the patient.

\section{Discussion}

Schwannomas may occur in various parts of the body.
They are common in the head and limbs (5). They have been reported in the prostate, spermatic cord, testicles (6), bladder (7), and seminal vesicles (8). This tumor is exceedingly rare in the penis. Schwannomas of the penis were first described in 1968 (9). Penile schwannomas are mostly benign. Nguyen et al. showed 25 cases had been reported by 2016. The locations of the tumors were diverse. The average age of the patients was 39.2 years (5).

Schwannomas are usually a solitary asymptomatic tumor that is painless and slow growing. However, penile schwannomas have been associated with painful intercourse, erectile dysfunction, and penile curvature (10). Peyronie's disease, fibrosis after intracavernosal injections, lipomas, 

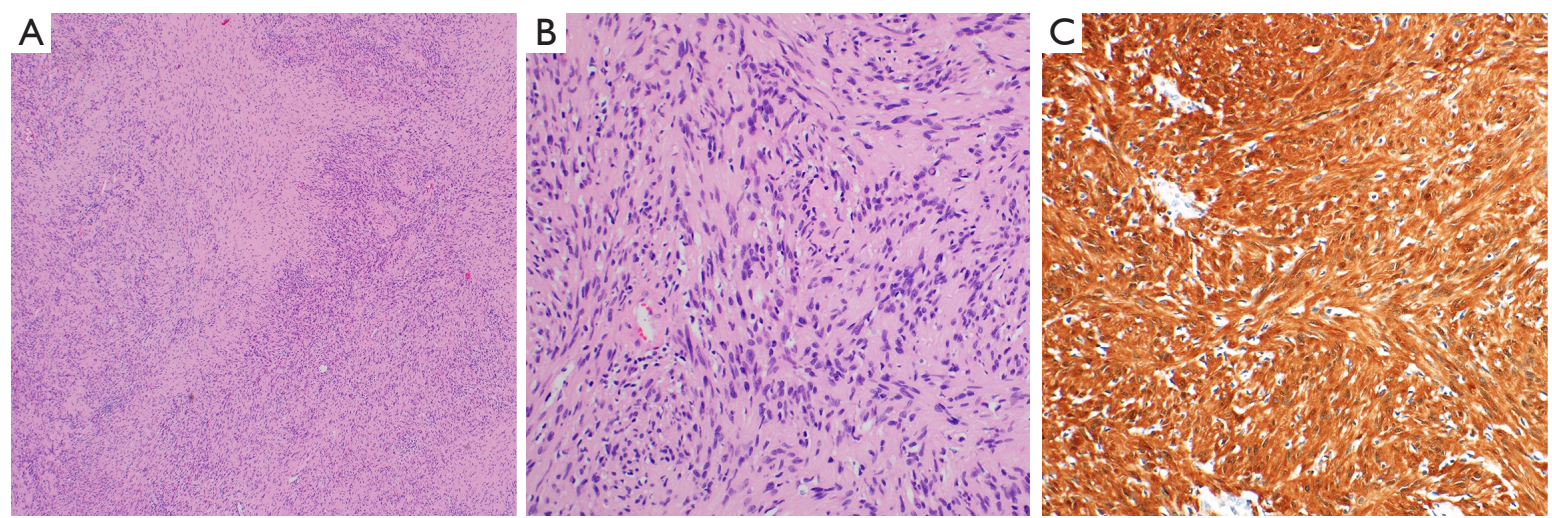

Figure 4 Pathologic findings of the penile schwannoma. (A) Microscopic findings of excised specimen show the typical biphasic pattern composed of alternating Antoni A and Antoni B areas. [hematoxylin and eosin (H\&E), x40]. (B) Tumor cells show nuclear palisading with tapered ends interspersed with collagen fibers (H\&E, ×200). (C) Immunohistochemical staining of S-100 show strong and diffuse expression in tumor cells (S-100 immunohistochemical staining $\times 200)$.

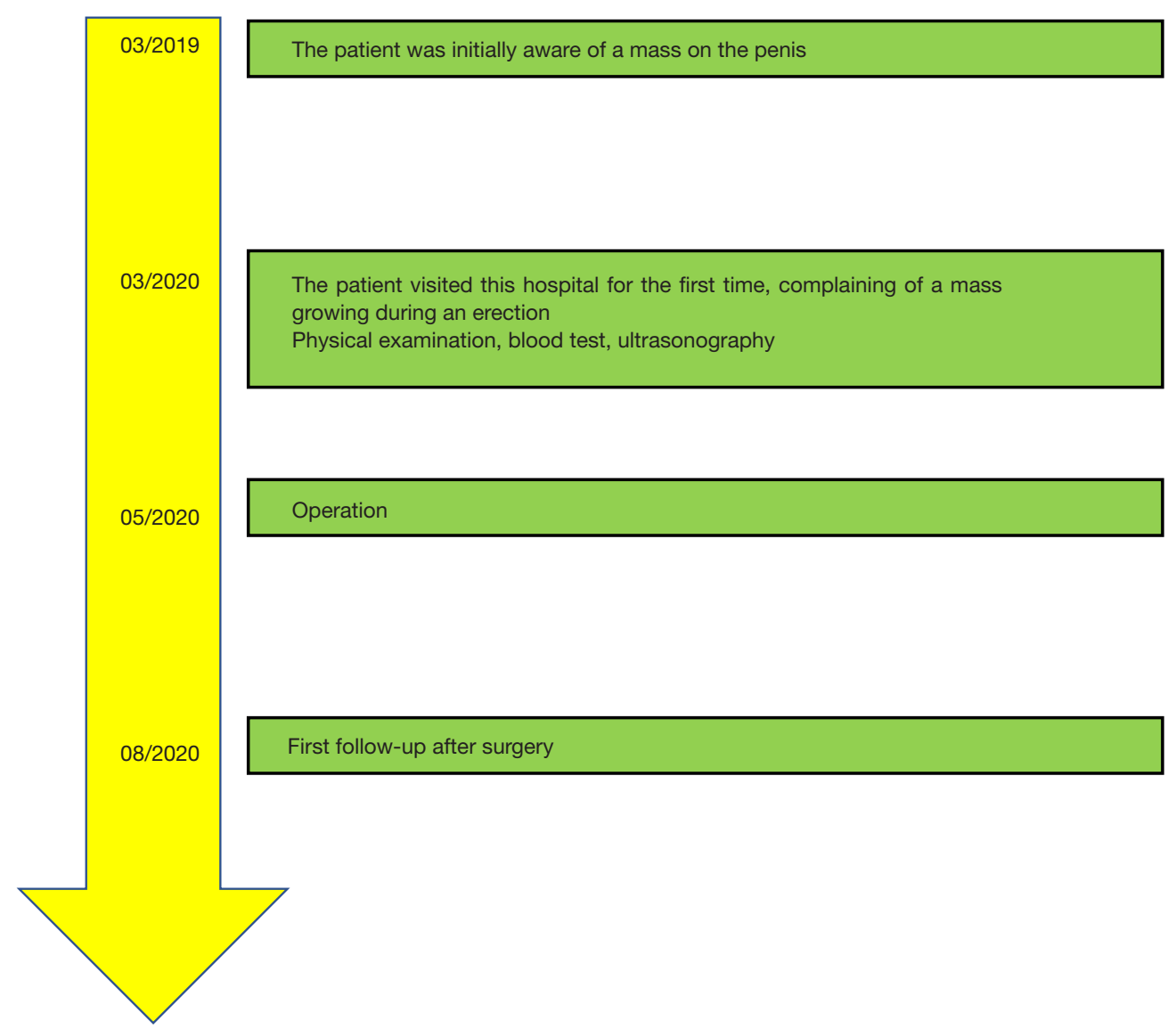

Figure 5 The patient's follow-up timeline. 
leiomyomas, and sarcomas should be ruled out for diagnosis. In this case, the patient complained that the size of the tumor increased during penile erection. However, during surgery, we could not find any blood vessels that supplied the tumor. It seems that the tumor caused by penile erection had been pushed up and looked enlarged. The patient said there was no sexual dysfunction during the three-month follow-up period.

Ultrasonography is less useful in diagnosing Schwannomas. Ultrasonography will usually show a welldemarcated hypoechoic mass with posterior acoustic enhancement (11). In some cases, there are unique findings: a targeted appearance because of a hyperechoic center and a hypoechoic periphery or a pseudocystic appearance (12). The vascularity of penile Schwannomas varies. Reynolds et al. reported increased vascularity with prominent arterial flow in $50 \%$ of schwannomas. CT should be performed to rule out malignancy, although most Schwannomas will be benign. Magnetic resonance imaging (MRI) can be a good diagnostic tool. Findings of schwannomas on MRI are described as masses with lowto-intermediated signal intensity on T1-weighted images and with inhomogeneous high-signal intensity on T2weighted images because of alternating Antoni A and B areas and secondary degenerative changes. In this case, only ultrasonography was performed, and the first impression was confused because of the high vascularity of the tumor. Adding MRI as a diagnostic tool would have made decision making easier (13).

The histopathologic finding was mainly composed of spindle-shaped cells, often palisading, with a mixture of Antoni A and Antoni B patterns. On immunohistochemical staining, S100 was almost $100 \%$ positive, findings suggestive of a benign lesion. On the other hand, Desmin and smooth muscle actin was negative. Neoplasms can also stain positively for vimentin, and/or epithelial membrane antigen (2). Schwannomas have the following subtypes: cellular schwannomas, plexiform schwannomas, and melanotic schwannomas. Cellular schwannomas tend to have a higher cellularity and mitotic rate. Moreover, their local recurrence rate is higher than conventional schwannomas. Plexiform schwannomas have many tissues of Antoni A-type and are prevalent on superficial locations. Melanotic schwannomas have a low prevalence and a potentially malignant risk. In particular, the differential diagnosis with melanoma or melanin-producing neoplasm is important (14). The type shown in this case report was suitable for conventional schwannomas.

Surgical resection is the primary treatment of choice for benign schwannomas. In surgery the tumor is relatively easy to separate off. It is recommended to have a complete resection with a negative surgical margin (5). In malignant cases, radiotherapy, chemotherapy, or combined chemoradiation therapy should be considered. These are called malignant peripheral nerve-sheath tumors associated with the nerve sheath, such as the Schwann cells, perineural cells, or fibroblasts (15). In rapidly enlarging or painful masses, malignancy should be suspected.

There have been several studies about benign penile schwannomas (Table 1). The most prevalent site is the penile shaft, and it was found in 18 cases $(51.8 \%)$. Excluding seven cases $(22.6 \%)$, a solitary mass was found in 24 cases. The median age of the cases was 39 years (range, 29-51 years), and the median mass size was $2.00 \mathrm{~cm}$ (range, 1.07-3.25 cm). All treatments were performed by surgical resection, and in particular, partial penectomy was performed in one case. There were no reports of recurrence.

This case report summarizes benign schwannomas that are difficult to detect in clinical practice to increase understanding of this disease to clinicians. However, inaccurate preoperative ultrasonography and short followup periods are the limitations.

\section{Conclusions}

Penile schwannomas are very rare tumors with a good prognosis. In ultrasonography, this can be confused with hemangioma because of high vascularity. Schwannomas can occur anywhere in the human body where nerves pass, and vascularity can vary. Therefore, if clinicians encounter an unfamiliar tumor, it is necessary to consider the possibility 


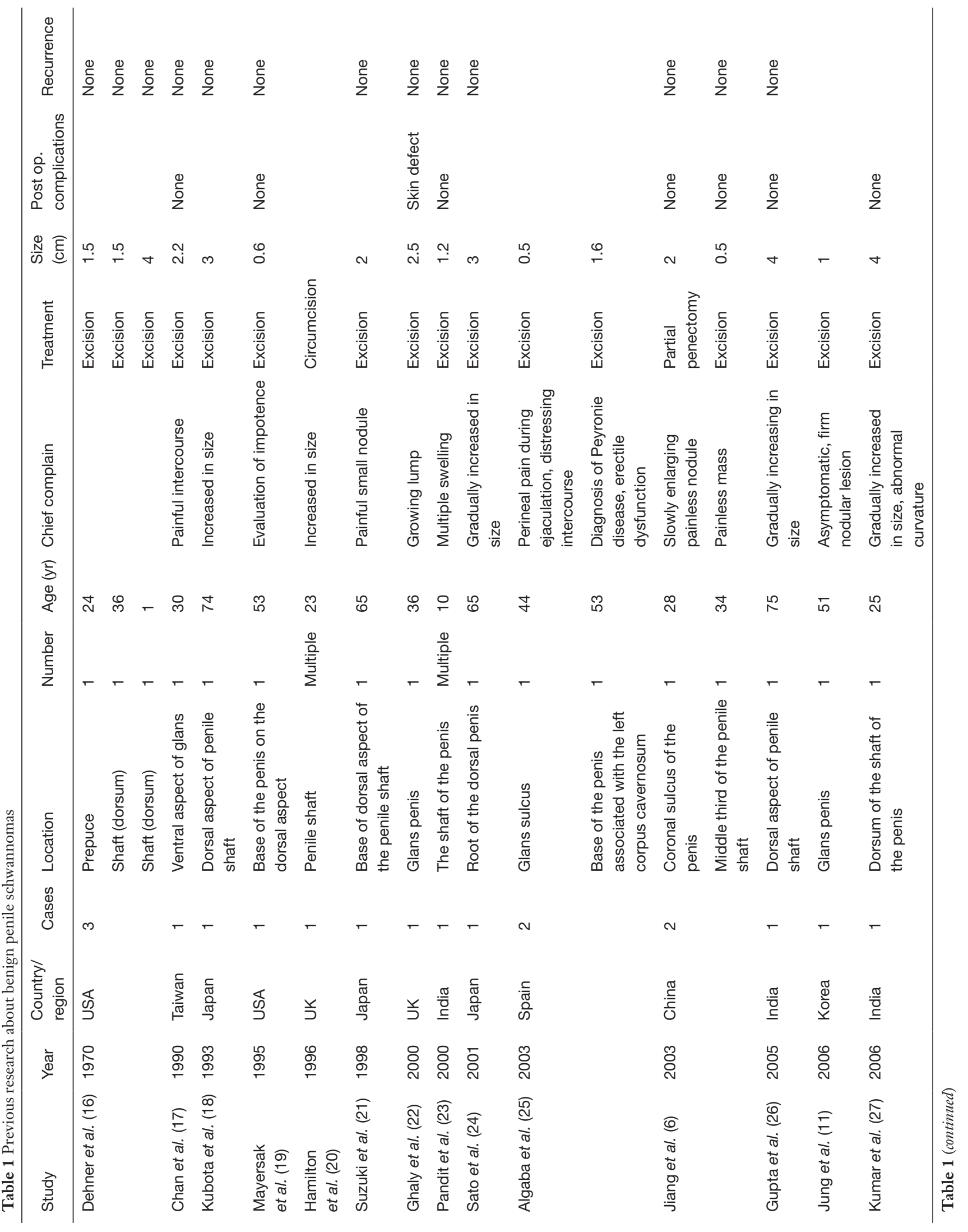




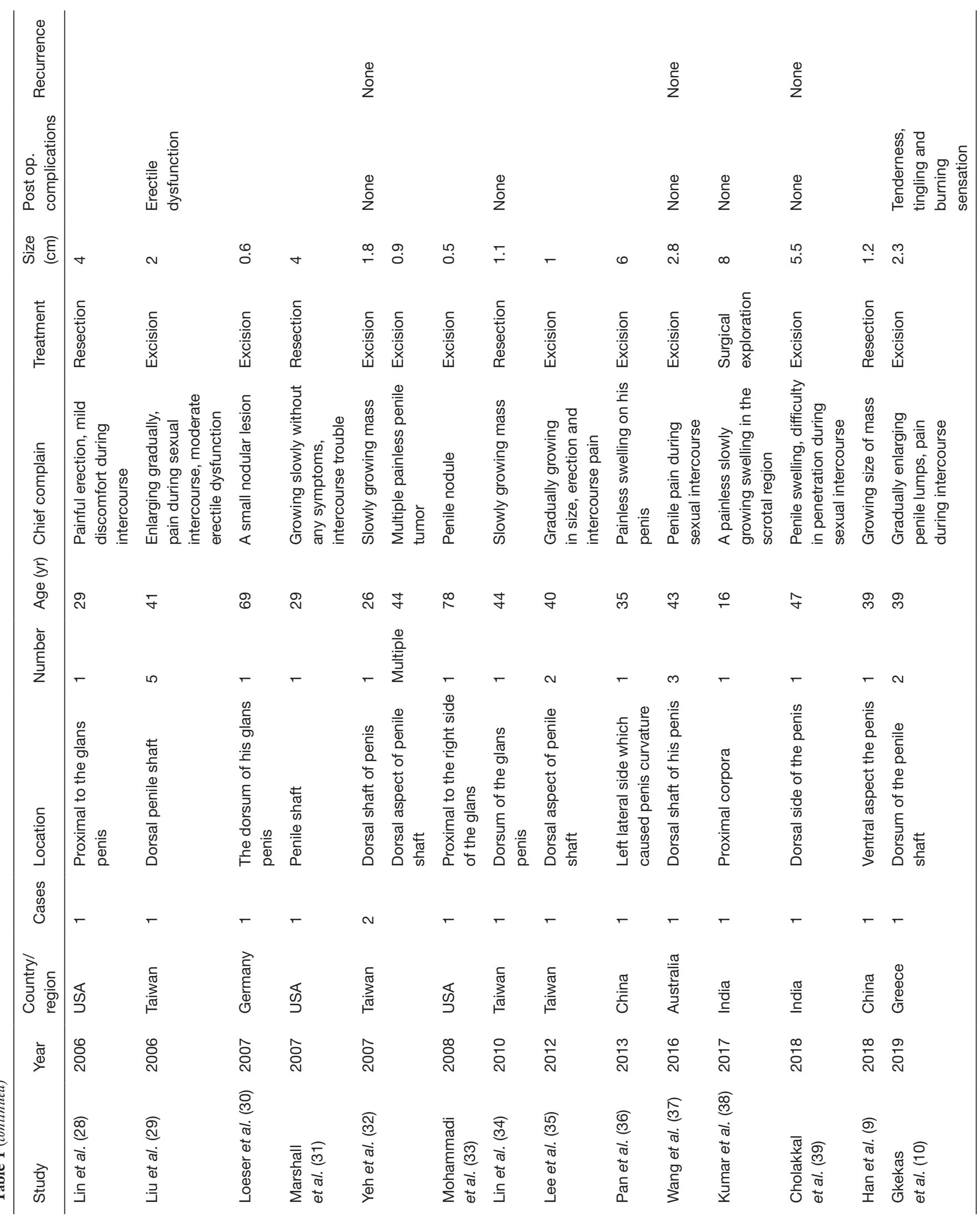


of schwannoma, even in rare cases.

\section{Acknowledgments}

This manuscript was prepared with the assistance of HARRISCO, an English-language scientific editing company.

Funding: This research was supported by the Soonchunhyang University Research Fund.

\section{Footnote}

Reporting Checklist: The authors have completed the CARE reporting checklist. Available at http://dx.doi.org/10.21037/ tau-21-239

Peer Review File: Available at http://dx.doi.org/10.21037/ tau-21-239

Conflicts of Interest: All authors have completed the ICMJE uniform disclosure form (available at http://dx.doi. org/10.21037/tau-21-239). The authors have no conflicts of interest to declare.

Ethical Statement: The authors are accountable for all aspects of the work in ensuring that questions related to the accuracy or integrity of any part of the work are appropriately investigated and resolved. All procedures performed in studies involving human participants were in accordance with the ethical standards of the institutional and/or national research committee(s) and with the Helsinki Declaration (as revised in 2013). Written informed consent was obtained from the patient.

Open Access Statement: This is an Open Access article distributed in accordance with the Creative Commons Attribution-NonCommercial-NoDerivs 4.0 International License (CC BY-NC-ND 4.0), which permits the noncommercial replication and distribution of the article with the strict proviso that no changes or edits are made and the original work is properly cited (including links to both the formal publication through the relevant DOI and the license). See: https://creativecommons.org/licenses/by-nc-nd/4.0/.

\section{References}

1. Evans DG, Huson SM, Donnai D, et al. A clinical study of type 2 neurofibromatosis. QJ Med 1992;84:603-18.
2. Hilton DA, Hanemann CO. Schwannomas and their pathogenesis. Brain Pathol 2014;24:205-20.

3. Evans DG, Moran A, King A, et al. Incidence of vestibular schwannoma and neurofibromatosis 2 in the North West of England over a 10-year period: higher incidence than previously thought. Otol Neurotol 2005;26:93-7.

4. Antinheimo J, Sankila R, Carpén O, et al. Populationbased analysis of sporadic and type 2 neurofibromatosisassociated meningiomas and schwannomas. Neurology 2000;54:71-6.

5. Nguyen AH, Smith ML, Maranda EL, et al. Clinical Features and Treatment of Penile Schwannoma: A Systematic Review. Clin Genitourin Cancer 2016;14:198-202.

6. Jiang R, Chen JH, Chen M, et al. Male genital schwannoma, review of 5 cases. Asian J Androl 2003;5:251-4.

7. Bakurov EE, Krakhotkin DV, Kucherenko OB. Isolated primary schwannoma of the urinary bladder- a case presentation. Urol Case Rep 2018;18:29-30.

8. Zhang Y, Zhao J, Xu P, et al. Multiple schwannoma of the seminal vesicle: A case report. Medicine (Baltimore) 2020;99:e21603.

9. Han H, Lei HE, Tian L, et al. Isolated penis schwannoma: A rare case report. Urol Case Rep 2018;21:12-3.

10. Gkekas C, Kalyvas V, Symeonidis EN, et al. Plexiform Schwannoma of the Penis: A Rare Subtype of Genital Schwannoma. Case Rep Urol 2019;2019:1752314.

11. Jung DC, Hwang SI, Jung SI, et al. Neurilemmoma of the glans penis: ultrasonography and magnetic resonance imaging findings. J Comput Assist Tomogr 2006;30:68-9.

12. Reynolds DL Jr, Jacobson JA, Inampudi P, et al. Sonographic characteristics of peripheral nerve sheath tumors. AJR Am J Roentgenol 2004;182:741-4.

13. Sakai F, Sone S, Kiyono K, et al. Intrathoracic neurogenic tumors: MR-pathologic correlation. AJR Am J Roentgenol 1992;159:279-83.

14. Rodriguez FJ, Folpe AL, Giannini C, et al. Pathology of peripheral nerve sheath tumors: diagnostic overview and update on selected diagnostic problems. Acta Neuropathol 2012;123:295-319.

15. Parekh N, Cockrell E, McMahon D. Malignant peripheral nerve sheath tumor of the penis: a case report and review of the literature. Urology 2013;81:1067-8.

16. Dehner LP, Smith BH. Soft tissue tumors of the penis. A clinicopathologic study of 46 cases. Cancer 1970;25:1431-47.

17. Chan WP, Chiang SS, Huang AH, et al. Penile frenulum 
neurilemoma: a rare and unusual genitourinary tract tumor. J Urol 1990;144:136-7.

18. Kubota Y, Nakada T, Yaguchi H, et al. Schwannoma of the penis. Urol Int 1993;51:111-3.

19. Mayersak JS, Viviano CJ, Babiarz JW. Schwannoma of the penis. J Urol 1995;153:1931-2.

20. Hamilton DL, Dare AJ, Chilton CP. Multiple neurilemmomas of the penis. Br J Urol 1996;78:468-9.

21. Suzuki Y, Ishigooka M, Tomaru M, et al. Schwannoma of the penis: report of a case and review of the literature. Int Urol Nephrol 1998;30:197-202.

22. Ghaly AF, Orange GV. Not every penile lump is a wart! Schwannoma of the penis. Int J STD AIDS 2000;11:199-200.

23. Pandit SK, Rattan KN, Gupta U, et al. Multiple neurilemmomas of the penis. Pediatr Surg Int 2000;16:457.

24. Sato D, Kase T, Tajima M, et al. Penile schwannoma. Int J Urol 2001;8:87-9.

25. Algaba F, Chivite A, Rodriguez-Villalba R, et al. Schwannoma of the penis: a report of 2 cases. J Androl 2003;24:651-2.

26. Gupta SK, Singh S, Kumar CP, et al. Fine needle aspiration cytology of a non-ulcerated penile lump. Cytopathology 2005;16:312-4.

27. Kumar GP, Sukumar S, Bhat SH, et al. Schwannoma of the penis: a common tumour at a rare site. Scand J Urol Nephrol 2006;40:166-7.

28. Lin EP, Marshall J, Bhatt S, et al. Penile schwannoma: sonographic features. J Ultrasound Med 2006;25:1447-50.

29. Liu WY, Chang CH, Tseng GC. Multiple penile schwannomas. MedGenMed 2006;8:35.

Cite this article as: Kim SH, Ahn H, Kim KH, Kim DS, Yang HJ. Penile schwannoma mistaken for hemangioma: a rare case report and literature review. Transl Androl Urol 2021;10(6):25122520. doi: $10.21037 /$ tau-21-239
30. Loeser A, Katzenberger T, Meuller JG, et al. Solitary schwannoma of the glans penis. Urology 2007;70:1007.e5-6.

31. Marshall J, Lin E, Dogra V, et al. Schwannoma of the penis: preservation of the neurovascular bundle. Urology 2007;70:373.e1-3.

32. Yeh CJ, Chuang WY, Huang ST, et al. Schwannoma of the penis: a report of two cases. Chang Gung Med J 2007;30:555-9.

33. Mohammadi A, Rosa M, Rhatigan R. Verocay body prominent schwannoma of penis: an unusual localization for this lesion. J Cutan Pathol 2008;35:1160-2.

34. Lin TC, Wu PY, Lin TY, et al. An infrequent plexiform variant of schwannoma of the glans penis: a rare finding. Asian J Androl 2010;12:455-7.

35. Lee $\mathrm{CH}, \mathrm{Wu} \mathrm{CJ}$, Chen YL, et al. Multiple penile schwannomas and their magnetic resonance imaging characteristics. J Androl 2012;33:167-9.

36. Pan F, Li B, Kunwar KJ, et al. Neuroimage: giant plexiform schwannoma of the penis. Eur Neurol 2013;69:118.

37. Wang L, Arachchi A, Makris A. A rare case of concurrent penile and spinal schwannomas. Urol Ann 2016;8:233-5.

38. Kumar U, Jha NK. Schwannoma of the penis, presenting as a scrotal mass, rare entity with an uncommon presentation. Urol Ann 2017;9:301-3.

39. Cholakkal S, V C S, Nachiketh G. Large Solitary Plexiform Neurofibroma of the Penis Without Erectile Dysfunction: a Case Report from Kerala. Indian J Surg 2018;80:90-2. 